\title{
Filipin-Sterol Complexes in Bean Rust- and Oat Crown Rust- Fungal/Plant Interactions: Freeze-Etch Electron Microscopy
}

\author{
D. E. HARder ${ }^{1, *}$ and K. Mendgen ${ }^{2}$ \\ 1 Agriculture Canada Research Station, Winnipeg, Manitoba, Canada \\ 2 Lehrstuhl Phytopathologie, Fakultät für Biologie, Universität Konstanz, Federal Republic of Germany \\ Contribution No. 1011. Winnipeg Research Stn. \\ Received November 18, 1981 \\ Accepted in revised form February 8, 1982
}

\begin{abstract}
Summary
Treatment with the polyene antibiotic filipin resulted in the formation of granular protuberances of the plasmamembranes of the mesophyll cells of bean (Phaseolus vulgaris) and oat (Avena sativa) plants, and of intercellular hyphal cells of the rust fungi Uromyces appendiculatus var. appendiculatus and Puccinia coronata var. avenae, as seen by freeze-etch electron microscopy. The granules were also occasionally seen in intracellular vesicles of $U$. appendiculatus. None were found in any intracellular organelles of plant or fungal tissue. The granules ranged in size from about $20-25 \mathrm{~nm}$ in the plant tissue and $21-27 \mathrm{~nm}$ in the fungal tissue. They were concluded to be filipin-sterol (FS) complexes. The extrahaustorial membranes of either bean or oat rustinfected tissue were generally devoid of FS complexes. The extrahaustorial membrane is continuous with the host plasmamembrane but appeared to have a lower sterol content as compared to the non-invaginated plasmamembrane. The results are discussed in relation to membrane associations at the host-parasite interface.
\end{abstract}

Keywords: Filipin-sterol complexes; freeze-etch; Uromyces appendiculatus; Phaseolus vulgaris; Puccinia coronata; Avena sativa.

\section{Introduction}

Previous studies on the ultrastructure of the intracellular host-parasite interface in the rust diseases have shown that there is a complex and highly specialized zone of interaction (see review by LiTTLEFIELD and HEATH 1979). Structurally, the most immediate contact between the fungal haustorium and host protoplast is the extrahaustorial membrane (EHM) of the host cell

\footnotetext{
* Correspondence and Reprints: Agriculture Canada Research
} Station, 195 Dafoe Road, Winnipeg, Manitoba, R3T 2M9, Canada. and the fungal haustorial wall, with a poorly defined region, the extrahaustorial matrix, occurring between these two structures. Although the structure of this zone is becoming better known, less is known of the chemical components involved. Although the EHM is an invagination of, and is continuous with the host cell plasmalemma, changes in structure and possible composition of this membrane are apparent during growth and maturation of the haustorium (LITTLEFIELD and BRACKER 1972). The nature of these changes are not clear.

The polyene antibiotic filipin binds specifically to cholesterol and related sterols (Norman et al. 1976) to form complexes which are readily observable in freezeetch replicas (RoBInson and KarNOVSKY 1980). This principle has been used to determine the distribution of cholesterol in a variety of animal and microbial cellular membranes. The method has been successfully used to study not only the distribution of cholesterol in different types of cell or organelle membranes (Elias et al. 1979, SOMmer et al. 1980), but of intramembrane distribution as well. Various regions of the plasmalemma of guinea pig sperm showed varying densities of filipin-cholesterol complexes (Elias et al. 1979). Most of the work with filipin has been done using animal tissue, and the filipin-sterol binding has generally been attributed to cholesterol. There are apparently no reports of the use of the filipin-sterol binding technique in plants. Although plant tissues generally do not contain cholesterol, the closely-related 
phytosterols such as stigmasterol or sitosterol predominate (DAVIES et al. 1964), thus the filipin binding technique may also be applicable to plant studies.

This study reports the use of filipin to determine the occurrence and distribution of sterol in the plasma membranes and extrahaustorial membranes in the Uromyces appendiculatus-Phaseolus vulgaris (bean rust) and Puccinia coronata-Avena sativa (oat crown rust) interactions.

\section{Materials and Methods}

\subsection{Host-Pathogen Combinations and Inoculation}

Leaves of Phaseolus vulgaris L. cv. Favorit and Avena sativa L. cv. Pendek were inoculated respectively with aqueous urediospore suspensions of compatible isolates of Uromyces appendiculatus (Pers. ex Pers.) Ung. var. appendiculatus and Puccinia coronata Cda. var. avenae Fras. and Led. The inoculated plants were incubated at high humidity overnight, then held in growth chambers at $20^{\circ} \mathrm{C}$ with an 18:6 hours light: dark cycle.

\subsection{Fixation and Filipin Treatment}

Seven days after inoculation pieces of infected leaf tissue about $1 \mathrm{~mm}^{2}$ were cut with a razor blade under a droplet of $2 \%$ glutaraldehyde in $0.1 \mathrm{M}$ phosphate buffer, $\mathrm{pH} 7.2$. The samples were then infiltrated with fixative under partial vacuum for 2 hours.

One hundred $\mu \mathrm{g}$ of filipin were dissolved in $0.1 \mathrm{ml}$ dimethylsulfoxide, then transferred to $10 \mathrm{ml}$ of $2 \%$ glutaraldehyde in $0.1 \mathrm{M}$ phosphate buffer, pH 7.2. The samples were placed in the filipin-glutaraldehyde mixture and incubated for 16 hours at $4{ }^{\circ} \mathrm{C}$. The control treatment was similar to that above but without filipin. An alternative treatment was to fix the tissue in $2 \%$ glutaraldehyde concurrently with $100 \mu \mathrm{g}$ of filipin at $20^{\circ} \mathrm{C}$ for 6 or 10 hours.

\subsection{Freezing and Freeze-Etching}

After the filipin-glutaraldehyde treatment the samples were washed over a 2 hours period in several changes of buffer. Concentrated glycerol in buffer was added drop-wise to the samples over a 30 minutes period to attain a final glycerol concentration of $30 \%$ in $0.1 \mathrm{M}$ buffer. The tissue pieces were allowed to stabilize in the glycerol for 2 hours, mounted flat on copper specimen holders, frozen by plunging them into liquified propane cooled by liquid nitrogen, and then were stored in liquid nitrogen.

The specimens were transferred to a Balzers freeze-etch apparatus precooled to $-170^{\circ} \mathrm{C}$. They were then shaved with the microtome $\mathrm{knife}$ at $-100^{\circ} \mathrm{C}$ until the desired depth into the tissue was attained. The knife assembly was held over the cut samples during a $0.5-1$ minute etch period at $-100^{\circ} \mathrm{C}$, followed immediately by shadowing with platinum and coating with carbon. The thickness of the coatings was controlled using a quartz thin-film monitor.

The replicas were floated and cleaned in $30 \%$ chromic acid-sulfuric acid, rinsed in double distilled water, and taken up on pioloformcoated nickel or copper electron microscope grids.

The nomenclature used to designate the fracture faces or surfaces is that of BRANTON et al. (1975).

\section{Results}

Treatment with filipin resulted in the formation of granular protuberances in the plasmamembranes of bean mesophyll cells (Fig. 1), oat mesophyll cells (Fig. 2) and of rust fungal intercellular hyphae (Fig. 3). The results were similar for both $U$. appendiculatus and $P$. coronata avenae. Although the protuberances were readily found after 6 or 10 hours treatment with filipin, they were somewhat more uniformly distributed throughout the tissue blocks after 16 hours treatment. The protuberances were not found in either host plant (Fig. 4) or fungal tissue (Fig. 5) treated similarly but without filipin. In plant tissue the protuberances were found only on the plasmalemma; none were found in organelles such as mitochondria and chloroplasts. In fungal hyphae the internal organelles were also generally protuberance-free although in some instances isolated vesicle-like bodies were coated with granules (Fig. 6).

The granules varied somewhat in size, ranging from about $20-25 \mathrm{~nm}$ in the bean and oat tissue to about $21-27 \mathrm{~nm}$ in the fungal tissue. These dimensions agree closely with the average of $20-25 \mathrm{~nm}$ reported generally for filipin-cholesterol complexes (RoBINSON and KARNOVSKY 1980). The protuberances in the plant and fungal plasmamembranes are concluded to be filipinsterol (FS) complexes.

Counts of FS complexes were taken over six random $1-\mu \mathrm{m}^{2}$ portions of four plasmamembranes of $P$. vulgaris or $U$. appendiculatus. In bean tissue the counts ranged from ca. 120 to 230 , with a mean of 194 granules $/ \mu \mathrm{m}^{2}$, while in the fungal tissue counts ranged from ca. 175 to 320 , with a mean of 248 granules $/ \mu \mathrm{m}^{2}$. Similar counts were obtained for $A$. sativa $\left(185\right.$ granules $\left./ \mu^{2}{ }^{2}\right)$ and $P$. coronata (245 granules $/ \mu \mathrm{m}^{2}$ ). The extrahaustorial membranes were generally free of FS complexes in either bean rust (Fig. 7) or oat crown rust (Fig. 8) infections. The protuberances on the extrahaustorial membranes in Figs. 7 and 8 were not considered to be FS complexes. Various protuberances, depressions or "wrinkles" were seen in the extrahaustorial membranes in either $U$. appendiculatus or $P$. coronata/host interactions where filipin was excluded (Figs. 12 and 13). Considerable variation has been encountered in the surface topography of extrahaustorial membranes in freeze-etch preparations of rust fungal/plant interactions and there appears to be increased wrinkling and distortion of the membrane with increasing haustorial age, or it is affected by the physiologic condition (e.g. level of compatibility) of the interaction (unpublished). 

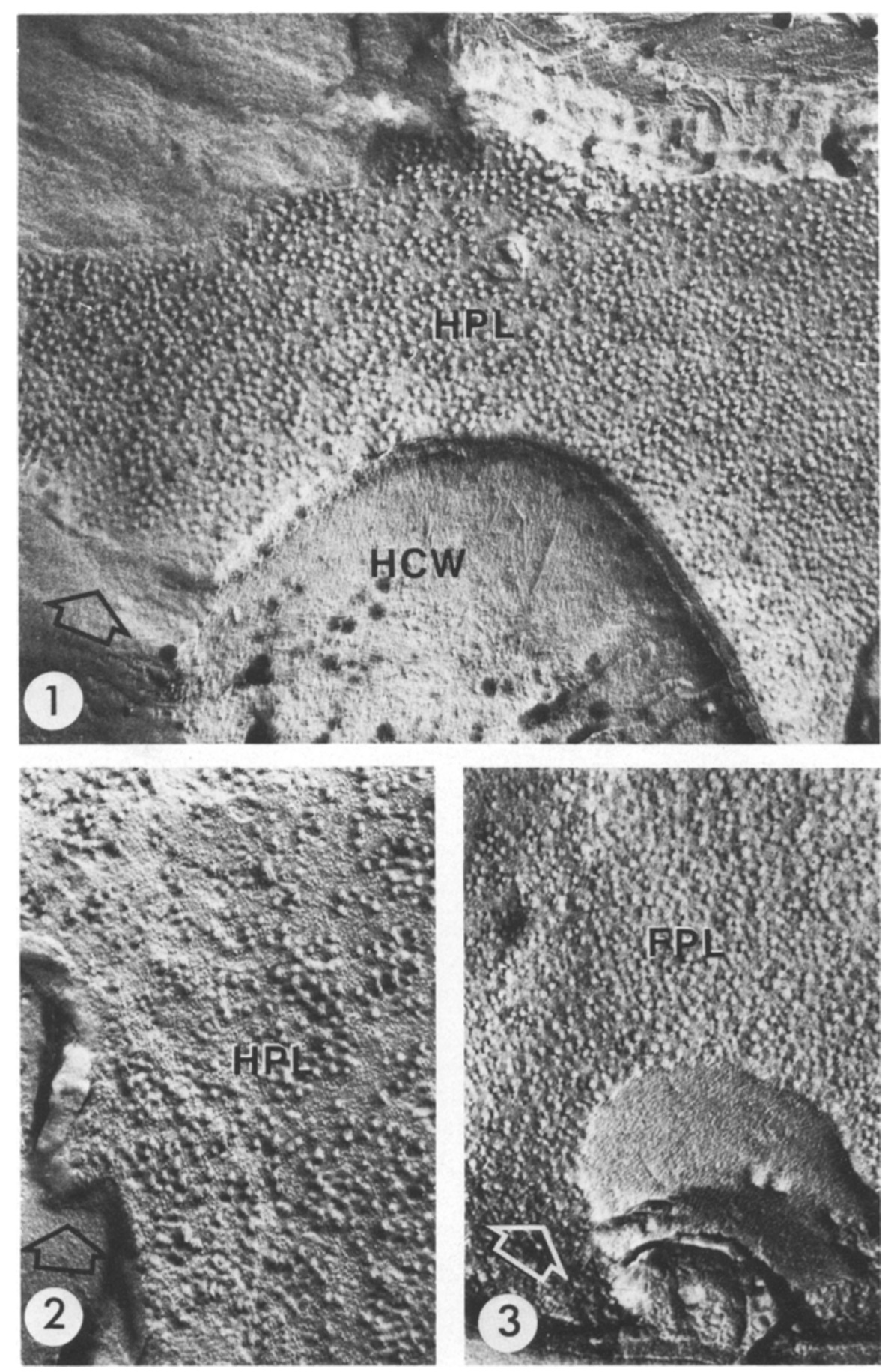

Abbreviations used in plates and figure legends

$E S$ exoplasmic surface, $E M$ extrahaustorial matrix, $E H M$ extrahaustorial membrane, $F S$ filipin-sterol complex, $F C W$ fungal cell wall, $F P L$ fungal plasmalemma, GLT glutaraldehyde, $H$ haustorium, $H W$ host cell wall, $H P L$ host plasmalemma, $M$ mitochondria, $N$ nucleus, $P$ protoplasm, $P F$ protoplasmic face, $V$ vesicle-like body. The large open arrows indicate the direction of shadowing

Fig. 1. A portion of the plasmalemma (ES) of a bean mesophyll cell with granules, $20-25 \mathrm{~nm}$ in size, distributed over the membrane. Git. 2 hours; - filipin, 16 hours. $\times 36,900$

Fig. 2. Oat mesophyll cell plasmalemma (PF) studded with filipin-sterol complexes. Git. - filipin, 10 hours. $\times 40,100$

Fig. 3. Plasmalemma (PF) of an intercellular hyphal cell of Uromyces appendiculatus studded with filipin-sterol complexes. Git. 2 hours; glt. filipin, 16 hours. $\times 37,300$ 

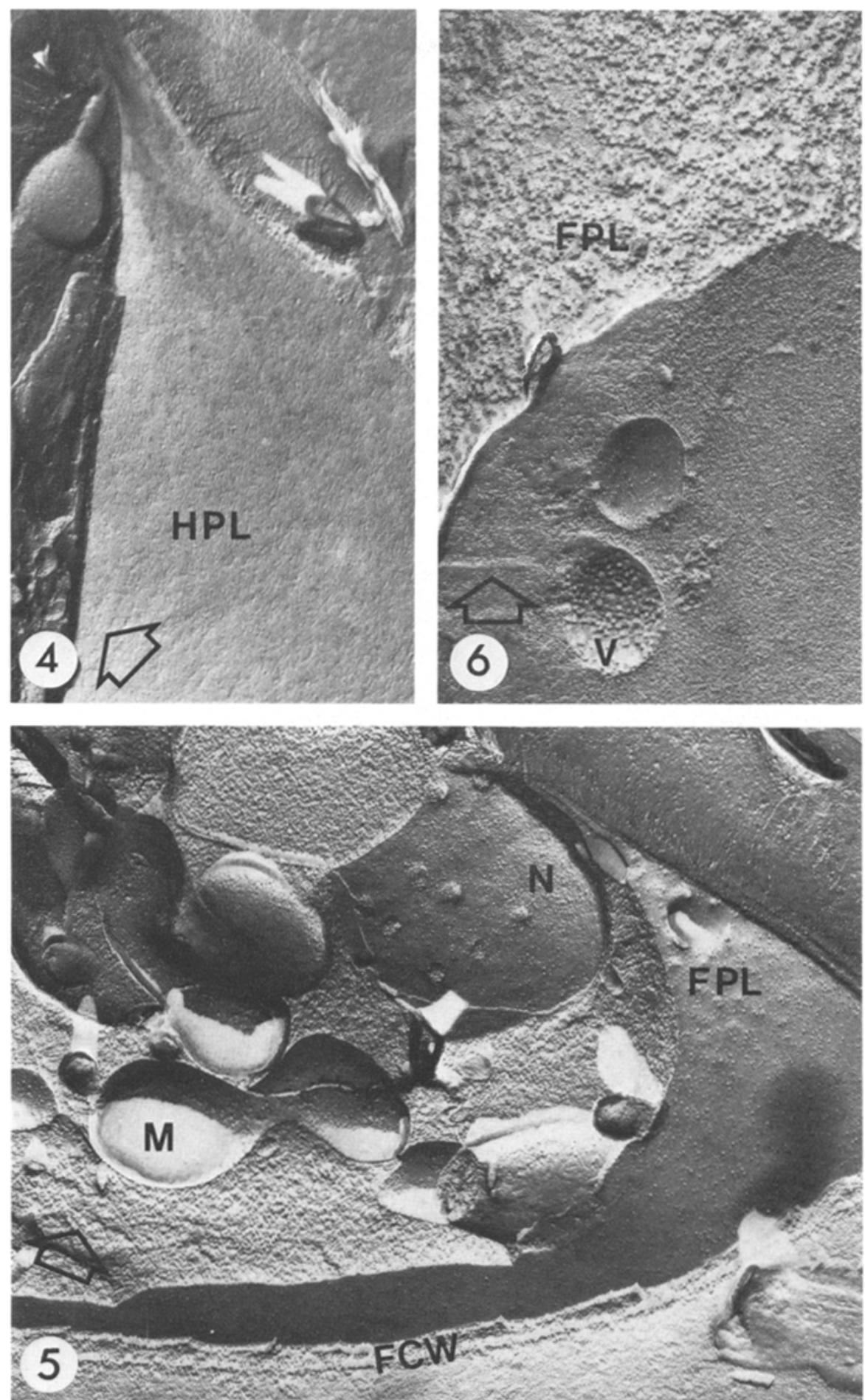

Fig. 4. Plasmalemma (ES) of a bean mesophyll cell in the absence of filipin. Glt. -2 hours; Glt. -DMSO, 6 hours. $\times 32,000$

Fig. 5. Intercellular hyphal cell of Uromyces appendiculatus in the absence of filipin. There are no filipin-sterol complexes on the plasmalemma on any of the intracellular structures. The plasmalemma (PF) is studded with intramembrane particles. Glt. -2 hours; Glt. - DMSO, 6 hours. $\times 32,900$

Fig. 6. Intercellular hyphal cell of Uromyces appendiculatus. The plasmalemma (PF) and an intracellular vesicle-like body are coated with filipinsterol complexes. Glt. -2 hours; glt. - filipin, 6 hours. $\times 28,200$ 

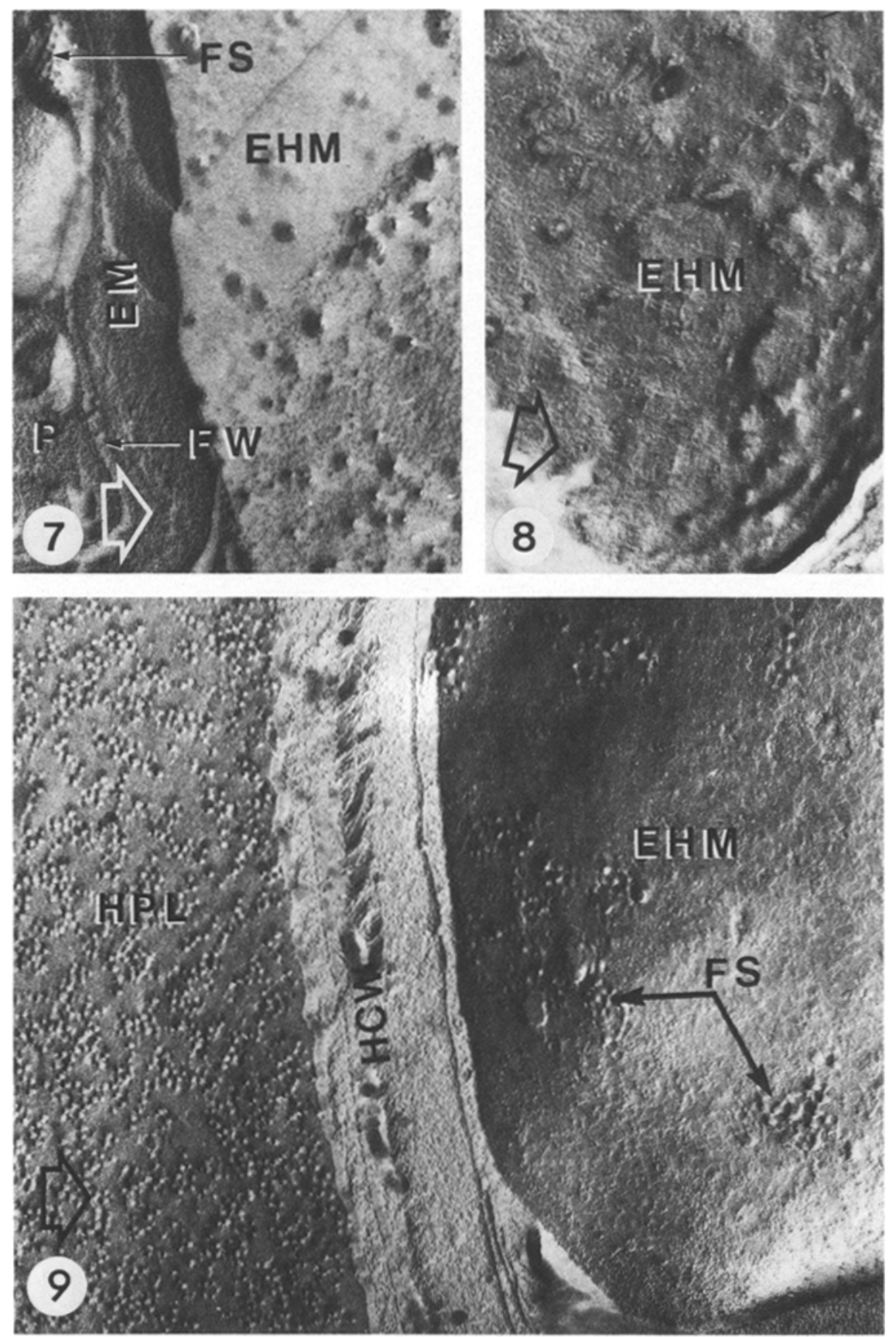

Fig. 7. A portion of a haustorium of Uromyces appendiculatus. Although there are protuberances on the extrahaustorial membrane (ES), these are not concluded to be filipin-sterol complexes. Glt. -2 hours; glt. - filipin, 16 hours. $\times 41,000$

Fig. 8. A representative portion of a haustorium of Puccinia coronata. There are no apparent filipin-sterol complexes on the extrahaustorial membrane (ES). Glt. -2 hours; glt. - filipin, 10 hours. $\times 40,000$

Fig. 9. A portion of a haustorium of Uromyces appendiculatus in the right-hand portion of the figure. The host plasmamembrane in an adjacent host cell is coated with filipin-sterol complexes, but there are only a few apparent complexes on the extrahaustorial membrane (PF). Glt. 2 hours; glt. - filipin, 6 hours. $\times 30,600$ 

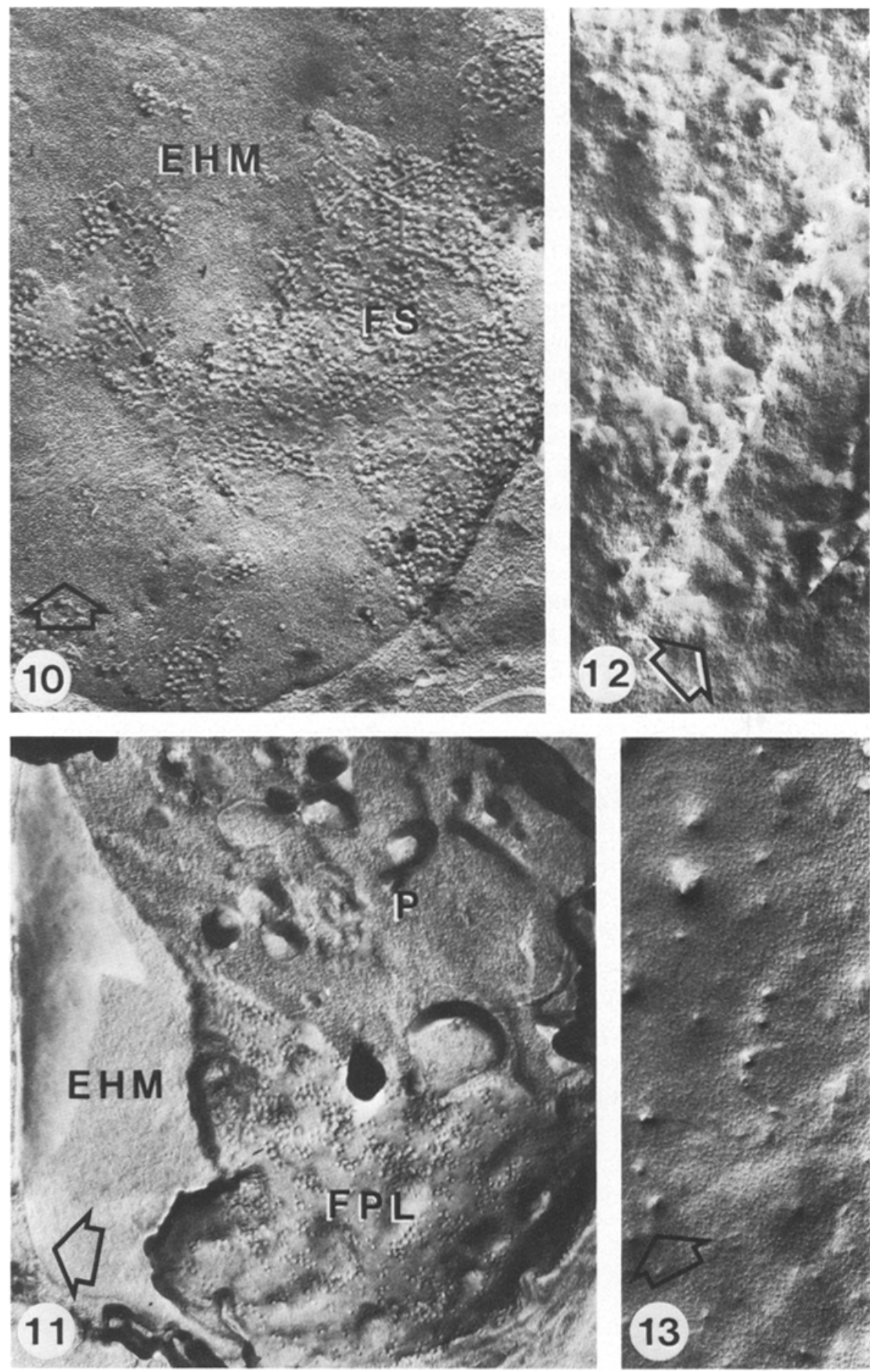

Fig. 10. A haustorium of Uromyces appendiculatus with some patches of apparent filipin-sterol complexes on the EHM. The granules occur mainly in somewhat raised areas with a smooth surface (ES) between the granules. Most of the EHM shows the PF. Glt. -2 hours; glt. - filipin, 6 hours. $\times 25,700$

Fig. 11. A complex fracture through a haustorium of Puccinia coronata. Filipin-sterol complexes are evident on the fungal plasmalemma (ES) but there are none on the extrahaustorial membrane (ES). Glt. -2 hours: glt. - filipin. 10 hours. $\times 31,000$

Figs. 12 and 13. Portions of the extrahaustorial membranes in Uromyces appendiculatus (Fig. 12) and Puccinia coronata (Fig. 13)/host interactions processed for freeze-etching without filipin. There are protuberances or depressions in the extrahaustorial membranes of both interactions. Fig. $12 \times 47,000$; Fig. $13 \times 39,000$ 
Of 42 haustoria examined in filipin-treated bean or oat tissue where a surface or face of the EHM was exposed, only five showed signs of FS complexes. Fig. 9 shows a portion of an EHM with a few apparent FS complexes. The latter haustorium was located in a mesophyll cell adjacent to another host cell in which the plasmalemma was well-studded with complexes. In the haustorium in Fig. 10 there were patches of granules over part of the EHM. In Fig. 10 most of the EHM that is visible is the protoplasmic face (PF) as judged by its finely-granular appearance. Where the larger granules occurred, they were in somewhat raised patches with a smooth surface between the granules, indicating an exoplasmic membrane face (ES). Occasionally tubule-like structures were associated with the patches of granules. The patchy distribution is also evident in Fig. 9, although the smooth-surfaced raised patches were not obvious. The reduced binding of filipin to the EHM may be due to changes in the composition of the membrane or to lack of penetration of filipin. In Fig. 6 the cytoplasmic vesicle in a fungal hypha with FS complexes indicates that filipin is capable of penetrating fungal hyphae after 6 hours treatment. Fig. 11 represents a complex fracture of a haustorium of $P$. coronata avenae showing the EHM, fungal plasmamembrane and haustorial cytoplasm. There were no complexes on the EHM, but some granules were apparent on the fungal plasmalemma. The granules in Fig. 11 were somewhat smaller than those on the intercellular hyphal plasmamembranes, but a similar fracture was obtained of another haustorium (not illustrated) in which granules on the fungal plasmamembrane were in the $20-25 \mathrm{~nm}$ size range. In both instances the number of FS complexes was lower than in comparable intercellular hyphal plasmamembranes, and they were distributed in a somewhat patchy manner. Vesicle-like bodies in crossfracture views of haustoria were found which were also coated with granules, similar to those in Fig. 6 . Penetration of filipin thus does not appear to have been a problem.

\section{Discussion}

The action of the polyene antibiotics is closely related to the occurrence of 3 -hydroxy sterols, mainly cholesterol, in the plasmamembranes of various organisms (FEINGOLD 1965, NoRMAN et al. 1976, WEBER and KINSKEY 1965). This affinity for membrane sterol and the ease of detection in freeze-etch replicas has led a number of workers to conclude that filipin-binding is a useful tool to study the distribution of membrane sterols. Most reports conclude that the binding is due to cholesterol, which is the dominant sterol in animal plasmamembranes. Although cholesterol is not a prominent sterol in plant tissue, the common phytosterols such as stigmasterol or sitosterol are closely related to cholesterol (DAviEs et al. 1964). In fungal tissue another cholesterol-related sterol, ergosterol, predominates (SEKUJA et al. 1979, TSUDA and TATUM 1961). Filipin formed complexes with ergosterol (SEKUJA et al. 1979) similar to those with cholesterol. The plasmalemma protuberances found in the plasmamembranes of the plant and fungal tissue in this study are concluded to be due to the complexing of filipin with sterols in these membranes.

The FS complexes are countable, and in theory the method should indicate relative concentrations of interor intramembrane sterols. Elias et al. (1979) obtained planar gradations in microheterogeneity of FS in artificial membranes and in membranes of cells and tissues. Sommer et al. (1980) indicated various regions of the sarcoplasmic reticulum of frog skeletal muscle to bind differentially with filipin. However, the level of filipin-binding may depend on a number of experimental variables such as solubility, incubation time, penetrability, temperature, etc. (EliAs et al. 1979). Furthermore, ROBINSON and KARNOVSKY (1980) indicated that filipin used without aldehyde fixation may result in intramembrane re-distribution of cholesterol due to the membrane disrupting action of filipin. The latter workers suggested that pre- or concurrent aldehyde fixation be carried out to preserve membrane cholesterol distribution. It was found that the incidence and distribution of filipin-cholesterol complexes compared well with published biochemical data. Concurrent or pre-fixation with glutaraldehyde was carried out in the present study, and there was a generally even though variable, distribution of FS complexes where they occurred in the plasmamembranes of host and fungal tissue. The relatively denser concentration of FS complexes in the fungal plasmamembrane indicates a higher concentration of sterol in the fungal tissue. This is in agreement with the generally high levels of sterols in fungal tissue (Tsuda and ТАтUм 1961 and references).

In the present study the FS complexes in plant tissue were confined to the plasmamembrane. This is in general agreement with work on animal tissue where no complexes were found in the nuclear envelope or mitochondrial membranes (EliAs et al. 1979) or they were the most concentrated in the plasmamembrane (Sommer et al. 1980). In fungal tissues, in addition to 
the plasmamembrane, large vesicle-like structures, presumably sterol-containing lipid bodies, were coated with granules.

The results of the present study indicate that the extrahaustorial membranes in the bean rust and oat crown rust interactions contained less sterol than the respective host plasmamembranes. The EHM is an extension of the plasmamembrane, and it would be surprising to find no sterol in the EHM. Complete lack of filipin-binding does not mean that sterols are entirely absent, as a threshold level of sterol is apparently necessary for binding to occur (ELLAs et al. 1979). Newly synthesized EHM may contain below-threshold levels of sterol, but in some instances there were also apparent isolated areas of higher sterol content, as indicated by the occurrence of patches of FS complexes. The raised patches have the appearance of foreign material adhering to the EHM, but there is no logical source of this material. Furthermore, in Figs. 9 and 10 it is the protoplasmic face (PF) of each EHM which is exposed. It is most likely that the raised smoothsurfaced patches with the FS complexes are areas of the outer leaflet of the EHM with the exoplasmic surface (ES) exposed. This may initially suggest that the FS complexes occur only on the outer leaflet, and most were stripped away during fracturing. However, this is most unlikely, as current models of FS complexes involve both leaflets of the membrane (DE KRUIJFF and DEMEL 1974) or mainly the inner leaflet (ELIAS et al. 1979). In PF views the FS complexes are usually sharper in outline than in ES views (Elias et al. 1979). The best explanation is that the patches represent localized areas of higher sterol content, and the two leaflets may have been somewhat more resistant to fracturing in those areas where the FS complexes occurred. These may represent remnants of plasmamembrane in the newly synthesized EHM.

Although FS complexes were encountered only in a few extrahaustorial membranes their consistent appearance when they occurred indicates that they were not chance occurrences. The extrahaustorial membranes in Figs. 9 and 10 were relatively smooth, and these may represent a stage, possibly relatively early, of haustorial growth. There is as yet insufficient information to assess the age of haustoria in freeze-etch preparations, but their surfaces appear to become more wrinkled and distorted with age (unpublished). From conventional transmission electron microscopy it is evident that the EHM is dynamic, and undergoes morphological changes as the haustorium ages (LITTLEFIELD and BRACKER 1972, and our own unpublished observations). A lower sterol content in the EHM may in part reflect some of these changes.

Although the functions of membrane sterols are not entirely clear, it is apparent that cholesterol greatly influences membrane function (SOMMER et al. 1980 and references). The extrahaustorial membrane is unique in the sense that there is direct continuity between this membrane and host endoplasmic reticulum (ER)-type of membrane in a number of host-rust fungal interactions (see Littlefield and Heath 1979). Normally there are few such direct associations between the plasmalemma and ER. Plasmamembranes normally contain considerably more lipid than do ER membranes (Morré and Mollenhauer 1974). Possibly the reduced level of sterol in the extrahaustorial membrane results in greater compatibility with the ER-type membrane, making direct fusion possible. Any function that the extrahaustorial membrane may have in the control of the exchange of metabolites between host and fungus is still speculative. If there is any such role, the change in sterol content may affect physical properties such as permeability, thus influencing exchange.

Conventional methods of biochemical analysis have generally provided little insight into the biochemistry of interactions at the host-parasite interface in the rust diseases. More precise methods which locate chemical components and/or changes at the intracellular level are needed to better understand the host-parasite interface. Ultrastructural cytochemistry appears to offer an advance in methods used to investigate this zone. However, the array of cytochemical tests as yet available are limited, and this field requires further development. The present study reports the use of one such test to investigate the host-pathogen interface.

\section{Acknowledgements}

The technical assistance of Mrs. Christine GIELE is gratefully acknowledged. Prof. H. PlatTNER kindly provided freeze-etch facilities and helpful advice. The Upjohn Co., Kalamazoo, Mich., is thanked for the gift of filipin. The Deutsche Forschungsgemeinschaft provided a research grant (ME523/9).

\section{References}

Branton, D., Bullivant, S., Gilula, N., Karnovsky, M. J., Moor, H., Muhlethaler, K., Northcote, D. H., Packer, L., Satir, D., SPeth, V., Staehlin, L. A., Steere, R. S., Weinstein, R. S., 1975: Freeze-etching nomenclature. Science 190, 54-56.

Davies, W. E., Goodwin, T. W., Mercier, E. I., 1964: The identification and determination of plant sterols. In: The Determination of Sterols. (Monograph, No. 2), pp. 38-50. London: The Society for Analytical Chemistry. 
De KruijfF, B., Demel, R. A., 1974: Polyene antibiotics-sterol interactions in the membranes of Acholeplasma laidlawii cells and lecithin liposomes. III. Molecular structure of the polyene antibiotics-cholesterol complexes. Biochim. biophys. Acta 339, $57-70$.

Elias, P. M., Friend, D. S., Goerke, J., 1979: Membrane sterol heterogeneity. Freeze-fracture detection with saponins and filipin. J. Histochem. Cytochem. 27, 1247-1260.

FEINGOLD, D. S., 1965: The action of amphotericin B on Mycoplasma laidlawii. Biochem. Biophys. Res. Commun. 19, $261-267$.

LITTLEFIELD, L. J., BRACKER, C. E., 1972: Ultrastructural specialization of the host-pathogen interface in rust-infected flax. Protoplasma 74, $271-305$.

- HeATH, M. C., 1979: Ultrastructure of Rust Fungi. New YorkSan Francisco-London: Academic Press.

Morré, D. J., Mollenhauer, H. H., 1974: The endomembrane concept: a functional integration of endoplasmic reticulum and Golgi apparatus. In: Dynamic Aspects of Plant Ultrastructure (RoBARDS, A. W., ed.), pp. 84-137. London: McGraw-Hill.
Norman, A. V., Spielvogel, A. M., Wong, R. G., 1976: Polyene antibiotic-sterol interaction. Adv. Lipid Res. 14, 127-170.

RoBInSON, J. M., KARNOvsKy, M. J., 1980: Evaluation of the polyene antibiotic filipin as a cytochemical probe for membrane cholesterol. J. Histochem. Cytochem. 28, $161-168$.

Sekuja, T., Kitajima, Y., Nozawa, Y., 1979: Effects of lipid-phase separation on the filipin action on membranes of ergosterolreplaced Tetrahymena cells, as studied by freeze-fracture electron microscopy. Biochim. biophys. Acta 550, 269-278.

SOMmer, J. R., DolBer, P. C., TAYLOR, I., 1980: Filipin-cholesterol complexes in the sarcoplasmic reticulum of frog skeletal muscle. J. Ultrastruct. Res. 72, 272-285:

TsudA, S., TATUM, E. L., 1961 : Intracellular crystalline ergosterol in Neuropsora. J. biophys. biochim. Cytol. 11, 171-177.

WEBER, M. M., KINSKY, S. C., 1965: Effect of cholesterol on the sensitivity of Mycoplasma laidlawii to the polyene antibiotic filipin. J. Bacteriol. 89, 306-312. 